\title{
Measurement properties of a multicultural weight-specific quality-of-life instrument for children and adolescents
}

\author{
Leo S. Morales • Todd C. Edwards • \\ Yvonne Flores • Lee Barr • Donald L. Patrick
}

Accepted: 22 August 2010/Published online: 6 September 2010

(C) The Author(s) 2010. This article is published with open access at Springerlink.com

\begin{abstract}
Purpose To evaluate the psychometric properties of a new multicultural weight-specific quality-of-life (QOL) measure for children and adolescents-Youth Quality-ofLife Instrument-Weight module (YQOL-W).

Methods Twenty-five candidate items were administered to 443 children and adolescents between 11 and 18 years of age, of whom $53 \%$ were female, $33 \%$ were white, $30 \%$ were African American and 37\% were Mexican American. Thirty-four percent had a healthy body mass index (BMI), $20 \%$ were overweight and $46 \%$ were obese.

Results Twenty-one of the original 25 candidate items were retained in the final instrument. Exploratory and
\end{abstract}

L. S. Morales ( $\square)$

Group Health Research Institute, 1730 Minor Avenue,

Suite 1600, Seattle, WA 98101, USA

e-mail: morales.1@ghc.org

T. C. Edwards · L. Barr

Department of Health Services, Seattle Quality of Life Group,

University of Washington, 1208 NE 43rd Street, Seattle,

WA 98195-9455, USA

Y. Flores

Jonsson Comprehensive Cancer Center, Department of Health

Services, School of Public Health, UCLA, Los Angeles,

CA 90095, USA

Y. Flores

Unidad de Investigación Epidemiológica y en Servicios de

Salud, Instituto Mexicano del Seguro Social, Cuernavaca,

Morelos, Mexico

D. L. Patrick

Seattle Quality of Life Group, University of Washington,

Box 359455, Seattle, WA 98195-9455, USA confirmatory factor analyses (CFA) resulted in a onefactor (21 items, alpha $=0.97$ ) and a three-factor model including a Self factor (4 items, alpha $=0.90$ ), a Social factor (11 items, alpha $=0.95)$ and an Environment factor (5 items, alpha $=0.90)$. CFA found the three-factor model had better model fit $(P<0.05)$. Both the onefactor and three-factor scores were negatively correlated with BMI and the Children's Depression Inventory and positively correlated with generic quality of life, all at the $P<0.05$ level. The 1 -week test-retest intraclass correlation coefficients were 0.73 for Social, 0.71 for Self, 0.73 Environment and 0.77 for the one-factor model.

Conclusions The YQOL-W shows good reliability and validity for assessing weight-specific QOL in children and adolescents.

Keywords Quality of life · Obesity · Children · Adolescents · Minority health · Hispanic American · African American

$\begin{array}{ll}\text { Abbreviations } \\ \text { QOL } & \text { Quality of life } \\ \text { BMI } & \text { Body mass index } \\ \text { zBMI } & \text { Standardized z-score BMI } \\ \text { YQOL-W } & \text { Youth Quality-of-Life-Weight module } \\ \text { CDI } & \text { Children's depression index } \\ \text { KMO test } & \text { Kaiser-Meyer-Olkin } \\ \text { PCA } & \text { Principal components analysis } \\ \text { PAF } & \text { Principal axis factoring } \\ \text { CFI } & \text { Comparative fit index } \\ \text { TLI } & \text { Tucker-Lewis index } \\ \text { RMSEA } & \text { Root mean square error of approximation } \\ \text { ICC } & \text { Intra-class correlation coefficient }\end{array}$




\section{Introduction}

Obesity in childhood and adolescence is a growing public health concern in the United States (US) particularly in ethnic minority groups [1]. Results from a recent study using nationally representative data showed that $34 \%$ of children and adolescents in the US were either obese or at risk of becoming obese and that African American and Hispanic children and adolescents had higher rates of obesity and risk of obesity than their non-Hispanic white counterparts [2]. Obesity in childhood and adolescence puts individuals at increased risk for chronic conditions before and during adulthood. During childhood and adolescence, obesity is linked to type 2 diabetes, prediabetes, metabolic syndrome, polycystic ovarian syndrome and non-alcoholic fatty liver disease [3]. Childhood and adolescent obesity has also been linked to adult obesity and the chronic conditions associated with adult obesity such as diabetes and cardiovascular disease $[4,5]$.

Beyond the negative effects of physical health, obesity has negative impacts on the psychosocial well-being and the quality of life (QOL) of children and adolescents. QOL has been defined as youths' perception of their position in life in the context of the culture and value systems in which they live, and in relation to their goals, expectations, standards and concerns $[6,7]$. In this approach, youth define the important concepts and items themselves in relation to how being obese affects their fundamental physical, psychological and social needs. For example, youth need to have sufficient physical ability to keep up with peers and sufficient respect from others to allow them to participate in youth society [8].

Obesity has been characterized as a stigmatizing condition that leads to social exclusion and discrimination [9]. The specific areas of psychological well-being most seriously impacted by obesity are body image, self-esteem and emotional well-being [10]. A recent review found that obesity is associated with lower QOL in children and adolescents across multiple domains including overall health-related quality of life, social functioning, physical functioning and psychological well-being [11]. Among the QOL domains impacted by obesity, physical and social functioning appear to be the most affected with some evidence that emotional functioning is affected and minimal evidence of school functioning being affected [11]. These findings generally mirror the findings in studies of obesity's impacts on QOL in adults.

Quality-of-life instruments can be classified as either generic or condition specific, the difference being that generic QOL instruments are applicable to individuals with a wide range of conditions including healthy individuals, whereas condition-specific QOL instruments are only applicable to individuals with one condition. Examples of generic QOL instruments for youth include the PedsQL [12] and the Child Health and Illness Profile [13] and an example of a condition-specific QOL instrument is the IWQOL [14]. The main advantage of generic QOL instruments is that they facilitate comparisons among individuals with various conditions and without any conditions. The main advantage of condition-specific instruments over generic instruments is that they are more sensitive to the particular QOL impacts resulting from a specific condition.

The purpose of this study is to evaluate the psychometric properties of a new weight-specific measure of QOL for children and adolescents of 11-18 years of age-the Youth Quality of Life-Weight (YQOL-W). The development of YQOL-W was guided by the World Health Organization's (WHO) conceptualization of QOL. In general, QOL is a broad-ranging construct affected in complex ways by a person's physical health, psychological state, level of independence, social relationships, personal beliefs and relationships to the salient features of their environment. The (WHO) group on quality of life defined QOL as individuals' perception of their position in life in the context of the culture and value systems in which they live and in relation to their goals, expectations, standards and concerns [15].

A detailed description of the development of the YQOL$\mathrm{W}$ is provided elsewhere [16]. The YQOL-W contributes to the literature on the measurement of weight-specific QOL in youth because unlike currently available weight-specific QOL instruments, the content YQOL-W is based on over 50 in-depth interviews with African American, Mexican American and white youth rather than expert opinion [16]. This development approach ensures that the instrument content and wording of the items reflect the views and language of a wide range of ethnically diverse youth. Following the development of the YQOL-W item pool, a multisite survey study in Seattle, Washington, and Los Angeles, California, was conducted to generate data for the psychometric evaluation of the YQOL-W instrument.

\section{Methods}

\section{Study design}

A community-based sample of youth participants was recruited in Seattle, Washington and Los Angeles, California. Study flyers, advertisements and/or recruitment letters were disseminated through community centers, schools, clinics and youth programs. Recruitment was also conducted via health fairs and youth events and through health professionals and youth educators. Participants received an incentive of $\$ 20$ cash or gift card of equal 
value for completing a 40-min questionnaire and a brief anthropometric examination. Prior to administering the survey, parents or guardians were asked to provide the following information about the participant: date of birth, gender and any major medical conditions. Parents/guardians were also asked to provide signed informed consent for their child to participate in the study. All study materials including the parent questionnaire, consent forms and participant survey were approved by the Institutional Review Boards of the University of Washington and the University of California Los Angeles.

A randomly selected sub-sample of 30 participants in Seattle completed the weight-specific quality-of-life (YQOL-W) portion of the questionnaire approximately 1 week after the initial survey to assess test-retest reliability. The repeat survey took approximately $15 \mathrm{~min}$ to complete, and participants were offered a $\$ 15$ incentive to complete the survey.

\section{Participants}

This study was limited to participants of 11-18 years of age. Potential participants were excluded if they were not African American, Mexican American or white, or if they had been told by a doctor that they had a major comorbid condition that had a greater impact on their life than weight (as judged by the youth's primary caregiver). The sample was stratified such that approximately equal numbers of participants were recruited with respect to gender (male, female), age [11-18], race/ethnicity (white, African American and Mexican American) and standardized body mass index (zBMI) (healthy, overweight and obese) resulting in a total of 36 recruitment cells. Participants were screened and recruited until each cell was filled. Between Seattle and Los Angeles, a total of 454 participants were enrolled in the study and completed the survey. Of these, participants without missing data were retained for these analyses $(n=443)$.

\section{YQOL-W item pool}

The YQOL-W item pool consisted of 25 weight-specific items corresponding to three domains of conceptual framework for QOL in youth by Edwards et al. [6]. Briefly, this conceptual framework posits three domains of QOL consisting of Self, Social and Environment. The Self domain refers to a youth's feelings about himself or herself. The Social domain pertains to a youth's relationships with others including family and peer relationships. Finally, the Environment domain pertains to opportunities and obstacles in a youth's social and cultural milieu. All of the items were administered with an 11-point scale anchored by "not at all" (0) and "very much" (10).
Study measures

Measures of depressive symptoms, non-specific (generic) quality of life and weight status were included in this study to evaluate the construct validity of the YQOL-W. Children's Depression Inventory (CDI) short form is a 10-item, self-report, symptom-oriented instrument designed to discriminate between children and youth aged 7-18 years with a psychiatric diagnosis of major depressive or dysthymic disorder as opposed to those with other psychiatric conditions or non-selected normals [17]. The CDI items were all administered with a 3-point scale, with higher scores indicating a higher level of depressive symptoms.

The YQOL-R is a 41-item generic measure of quality of life for youth [6, 18]. A single summary YQOL-R score was computed for each participant by performing a 0-100 linear transformation of each item score in the scale and then averaging among all the item scores. The scores were computed such that a higher score reflected a better quality of life.

Weight status was assigned based on standardized z-score body mass index (zBMI). Each participant's height and weight were measured following a standard protocol and were taken after the questionnaire was administered in order to avoid focusing the participants' attention on their own weight before undertaking the survey. The zBMI scores were calculated using age- and gender-specific national norms from the Centers for Disease Control and Prevention [19]. Percentile cutoffs were used to place participants into one of the three weight categories: healthy (zBMI $<85$ th percentile), overweight $(85$ th $-<95$ th percentile), obese ( $\geq 95$ th percentile).

Other covariates included in the analyses were age (11-14 or 15-18 years), gender and race/ethnicity (African American, Mexican American or white), all based on information provided by the participants' parents.

Statistical analysis

Prior to analyzing the data, out-of-range and missing values were checked against the paper and pencil surveys completed by the participants and inconsistencies were corrected. After data cleaning, responses to the YQOL-W items were recoded such that 10 indicated the highest possible QOL score.

Candidate YQOL-W items were characterized in terms of including item means, standard deviations, percent of responses at the floor (response $=0$ ) and ceiling (response $=10$ ), skewness, kurtosis and inter-item Pearson product-moment correlation coefficients. To determine whether there were a sufficient number of significant correlations among the items to justify exploratory factor analysis, we computed a Bartlett's test of sphericity 
coefficient [20] and Kaiser-Meyer-Olkin (KMO) test of sampling adequacy.

The number of factors extracted was based upon analyses including principal components analysis (PCA), principal axis factoring (PAF) and the examination of several criteria including the Kaiser-Guttman criteria $[21,22]$, the percent of variance explained [23], a scree plot [24], parallel analysis [25, 26] and the interpretability of the factors. For more information conducting exploratory factor analysis, see Pett et al. [23].

After establishing the number of factors to extract, orthogonal (Varimax) and oblique (Promax) factor rotations were computed. Following each rotation, the factor structure was examined to find the rotation method that produced the most interpretable simple structure. Items without a loading of 0.40 or higher on any factor and items with loadings of 0.40 or higher on multiple factors were considered for elimination from the item pool.

Confirmatory factor analysis was also applied to investigate the factor structure. In contrast to exploratory factor analysis, confirmatory factor analysis is hypothesis driven. We used confirmatory factor analysis to evaluate the fit of two alternative model specifications derived from the exploratory factor analysis: a one-factor and a three-factor model. The fit of each model was evaluated by standard fit indexes including comparative fit index (CFI), TuckerLewis index (TLI) and the root mean square error of approximation (RMSEA) and relative fit was assessed by contrasting the model log-likelihood values [27].

Coefficient alpha and item-scale correlations were computed for each of the resulting scales. Intraclass correlation coefficients were derived from two-way random effects ANOVA models to evaluate the test-retest reliability. Finally, construct validity was assessed by estimating correlation coefficients between the YQOL-W scores and the CDI, the YQOL-R and zBMI. Scale score were derived by linearly transforming items scores to a 0-100 score range then averaging the item score with other item in the same scale. Analyses were conducted with SPSS version 17 [28] and MPLUS version 5 [29].

\section{Results}

\section{Participant characteristics}

Of the 443 children and adolescents included this study, $53 \%$ were between 11 and 14 years of age and $47 \%$ were between 15 and 18 years of age, 53\% were female, 33\% were white, $30 \%$ were African American and $37 \%$ were Mexican American (Table 1). Thirty-six percent of the youths' mothers had high school or less education and 64\% had at least some college. Thirty-four percent had a healthy
Table 1 Sample characteristics $(n=443)$

\begin{tabular}{|c|c|c|}
\hline & $N$ & $\%$ \\
\hline \multicolumn{3}{|l|}{ Age in years } \\
\hline $11-14$ & 234 & 53 \\
\hline $15-18($ mean $\pm \mathrm{SD}=14.7 \pm 2.2)$ & 209 & 47 \\
\hline \multicolumn{3}{|l|}{ Gender } \\
\hline Female & 233 & 53 \\
\hline Male & 210 & 47 \\
\hline \multicolumn{3}{|l|}{ Race/ethnicity } \\
\hline Black/African American & 132 & 30 \\
\hline White/Caucasian & 145 & 33 \\
\hline Mexican American & 165 & 37 \\
\hline \multicolumn{3}{|l|}{ Mother's education } \\
\hline Less than HS & 75 & 18 \\
\hline HS/GED & 77 & 18 \\
\hline Some college & 128 & 31 \\
\hline College & 97 & 23 \\
\hline Masters or higher & 40 & 10 \\
\hline \multicolumn{3}{|l|}{ BMI category } \\
\hline Healthy & 149 & 34 \\
\hline Overweight & 89 & 20 \\
\hline Obese $($ mean $\pm \mathrm{SD}=27.1 \pm 6.8)$ & 204 & 46 \\
\hline \multicolumn{3}{|l|}{ Recruitment site } \\
\hline Seattle & 226 & 51 \\
\hline Los Angeles & 217 & 49 \\
\hline
\end{tabular}

Sample sizes within characteristics may not sum to $n=443$ due to missing values

BMI, 20\% were overweight and $46 \%$ were obese. Fifty-one percent of the sample was recruited in Seattle and $49 \%$ in Los Angeles.

Item descriptive statistics

Item means ranged from 6.41 to 9.12 with a possible range of $0-10$ (Table 2). The percent of responses at the floor (score $=0$ ) ranged from 1 to $11 \%$, and the percent of responses at the ceiling (score $=10$ ) ranged from 33 to $78 \%$. Items with ceiling responses exceeding $70 \%$ were considered for elimination. Item skewness ranged from -2.42 to -0.44 , indicating that item responses tended to bunch at the upper end of the QOL continuum, and item kurtosis ranged from -1.18 to 6.17 , indicating that the shapes of the response distributions varied from u-shaped to highly peaked (not shown in table).

Inter-item correlations

The average, smallest and largest inter-item correlations were $0.58,0.36$ and 0.87 , respectively. All correlation coefficients were significant at the $P<0.05$ level. Support 
Table 2 Content, domain assignment and descriptive statistics for YQOL-W item pool $(n=443)$

\begin{tabular}{|c|c|c|c|c|c|}
\hline (Item no.) brief item content & Domain & Mean & SD & $\%$ Floor & $\%$ Ceiling \\
\hline (1) Feel depressed & Self & 6.41 & 3.42 & 7 & 33 \\
\hline (2) Feel ashamed & Self & 6.65 & 3.41 & 7 & 36 \\
\hline (3) Uncomfortable with skinny people & Self & 6.72 & 3.59 & 10 & 40 \\
\hline (4) Hide my body & Self & 6.89 & 3.56 & 8 & 44 \\
\hline (5) Feel unattractive & Social & 7.19 & 3.38 & 7 & 45 \\
\hline (6) Avoid photographs & Social & 8.48 & 2.79 & 3 & 68 \\
\hline (7) Embarrassed to exercise & Social & 8.05 & 3.12 & 6 & 60 \\
\hline (8) Embarrassed to eat & Social & 8.33 & 2.86 & 3 & 66 \\
\hline (9) Avoid being noticed & Social & 8.59 & 2.63 & 3 & 68 \\
\hline (10) Worry what people saying & Social & 7.31 & 3.48 & 7 & 49 \\
\hline (11) Uncomfortable at social events & Social & 7.93 & 3.04 & 4 & 57 \\
\hline (12) Feel like a loser & Social & 7.80 & 3.31 & 7 & 59 \\
\hline (13) Down on myself & Item Dropped & 7.75 & 3.17 & 4 & 54 \\
\hline (14) Uncomfortable moving & Environment & 8.12 & 2.94 & 4 & 59 \\
\hline (15) Avoid exercise & Item Dropped & 8.74 & 2.48 & 3 & 70 \\
\hline (16) Avoid swim suits & Environment & 7.14 & 3.64 & 10 & 50 \\
\hline (17) Problems making friends & Item Dropped & 9.12 & 2.02 & 1 & 78 \\
\hline (18) Family & Item Dropped & 8.44 & 2.83 & 4 & 68 \\
\hline (19) Hard finding girlfriend or boyfriend & Social & 7.75 & 3.40 & 7 & 59 \\
\hline (20) People stare & Social & 8.31 & 2.97 & 4 & 66 \\
\hline (21) Not included & Social & 8.49 & 2.78 & 3 & 68 \\
\hline (22) Hard getting job & Social & 8.91 & 2.46 & 3 & 76 \\
\hline (23) Difficult wearing cloths & Environment & 7.00 & 3.69 & 11 & 47 \\
\hline (24) Difficult finding clothes & Environment & 7.46 & 3.52 & 9 & 53 \\
\hline (25) Hard to exercise & Environment & 8.14 & 2.96 & 5 & 59 \\
\hline
\end{tabular}

All items were administered with an 11-point scale with anchored by "not at all" (0) and "very much" (10). Items 13, 15, 17 and 18 were dropped due to statistical considerations

for conducting exploratory factor analysis was provided by Barlett's test of sphericity (chi-square $=9381.818$, df $=$ 231, $P<0.001$ ) and the KMO statistic $=0.97$. A KMO statistic of more than 0.90 is considered an outstanding support for exploratory analysis [23].

Factor analysis and reliability

The first four eigenvalues obtained from principal components analysis were $13.05,1.10,0.86$ and 0.77 explaining $62,67,71$ and $75 \%$, respectively, of the cumulative variance. These results suggested that two factors should be extracted based on the Kaiser-Guttman rule [30] or three factors based on the percent of variance explained using a $70 \%$ threshold. The first inflection point on the scree plot was at the fourth eigenvalue, suggesting that three or four factors should be extracted. Parallel analysis-performed on of the eigenvalues obtained from the principal axis factoring (using square of the multiple correlations)indicated that a maximum of two factors should be extracted.
With these results in hand, principal axis factoring was conducted extracting two, three and four factors, and the solutions were rotated using orthogonal (Varimax) and oblique (Promax) rotation methods. Overall, the threefactor models provided the best groupings of items with content pertaining to the Self, Social and Environment domains in separate factors. The two-factor models tended to group items with content from the Self and Social domains in one factor and items from the Environment domain in a second factor. The four-factor models resulted in three main factors and a small factor with two items that did not share similar content. Because scale developers recommend against factors with fewer than three items, we chose against a four-factor model [31]. Overall, the oblique rotations grouped items with similar content together better than the orthogonal rotations due to correlated domain scores. Correlated factors were also consistent with previous empirical research on youth QOL [18].

Inspection of the three-factor solutions resulting from principal axis factoring and oblique rotation resulted in the elimination of several items that were not strongly 
associated on one of the three factors (these items did not have factor loadings of 0.40 or greater on any one factor). These items were item 13 (Because of my weight I feel down on myself), item 15 (Because of my weight I try to avoid exercise), item 17 (Because of my weight I have problems making friends) and item 18 (My family makes me feel bad about my weight). After dropping items, the principal axis factoring and oblique rotation were repeated on the remaining items. When additional items were found to have weak factor loadings, they were dropped and the factor analyses were repeated again. This iterative process continued until no further item deletions were necessary. Before dropping any item, the study team reviewed the item's content and discussed the item's importance to the measurement of the relevant construct. In the case of item 16 (Because of my weight I avoid being seen in a swim suit), a decision was made to retain this item in spite of a factor loading $<0.40(0.36)$ due to what we learned about the importance of this item's content during the qualitative phases of this research [16].

The final factor loadings for the three-factor model obtained from principal factor analysis and oblique rotation are reported in Table 3. Going from left to right, the Social factor had 12 items with loadings ranging from 0.45 to 0.96; the Self factor had four items with loadings ranging in value from 0.51 to 0.98 ; and the Environment factor had five items with loadings ranging from 0.36 to 0.93 . The Pearson product-moment correlation coefficient for the Social and Self factor scores was 0.75; for the Social and Environment factors, it was 0.80; and for the Self and Environment factors, it was 0.71 .

Item-scale correlations and coefficient alpha for the Social, Self and Environment factors are reported in Table 4. Item-scale correlations for the Social factor ranged in value from 0.74 to 0.85 , and coefficient alpha for the factor was 0.95 . Item-scale correlations for the Self factor ranged in value from 0.75 to 0.85 and coefficient alpha for the factor was 0.90 . Dropping item 3 from the Self factor had a small positive effect on coefficient alpha, whereas dropping items 1,2 and 4 had a small negative effect coefficient alpha. Item-scale correlations for the Environment factor ranged in value from 0.73 to 0.84 , and coefficient alpha for the factor was 0.90. Dropping items 14, 23, 24 and 25 had a small negative effect on coefficient alpha.

Because of the high correlation between the Social, Environment and Self factors, we also considered a onefactor model. A one-factor model is consistent with previous research on quality of life in youth and therefore was conceptually appealing [18]. The results from a one-factor model are also reported in Table 3. The factor loadings for the one-factor model were $0.64-0.84$ and coefficient alpha was 0.97 . The item-scale correlations were $0.62-0.83$.
Table 3 Factor pattern matrix for YQOL-W for three-factor and one-factor models $(n=443)$

The three-factor solution was obtained by principal axis factoring with Promax rotation $(\kappa=4)$. The one-factor solution was obtained by principal axis factoring

Item loadings corresponding to the hypothesized factors are indicated by bold type

\begin{tabular}{|c|c|c|c|c|c|}
\hline \multirow[t]{2}{*}{ Item no. } & \multirow[t]{2}{*}{ Brief item content } & \multicolumn{3}{|c|}{ Three-factor model } & \multirow[t]{2}{*}{ One-factor mode } \\
\hline & & Social & Self & Environment & \\
\hline 9 & Avoid being noticed & 0.96 & -0.03 & -0.14 & 0.77 \\
\hline 6 & Avoid photographs & 0.85 & 0.08 & -0.16 & 0.74 \\
\hline 11 & Uncomfortable at social events & 0.84 & 0.05 & -0.01 & 0.85 \\
\hline 21 & Not included & 0.81 & -0.03 & 0.08 & 0.82 \\
\hline 20 & People stare & 0.70 & -0.01 & 0.20 & 0.84 \\
\hline 8 & Embarrassed to eat & 0.62 & 0.05 & 0.14 & 0.77 \\
\hline 7 & Embarrassed to exercise & 0.59 & 0.05 & 0.21 & 0.81 \\
\hline 12 & Feel like a loser & 0.57 & 0.15 & 0.14 & 0.81 \\
\hline 5 & Feel unattractive & 0.52 & 0.31 & 0.05 & 0.81 \\
\hline 22 & Hard getting a good job & 0.51 & -0.09 & 0.24 & 0.64 \\
\hline 10 & Worry what people say & 0.50 & 0.21 & 0.16 & 0.82 \\
\hline 19 & Hard finding a boyfriend or girlfriend & 0.45 & 0.07 & 0.31 & 0.78 \\
\hline 1 & Feel depressed & -0.04 & 0.98 & -0.06 & 0.74 \\
\hline 2 & Feel ashamed about my weight & -0.05 & 0.97 & 0.01 & 0.77 \\
\hline 3 & Uncomfortable with skinnier people & 0.14 & 0.60 & 0.02 & 0.66 \\
\hline 4 & Hide my body & 0.17 & 0.51 & 0.22 & 0.80 \\
\hline 24 & Difficult finding clothes & -0.08 & -0.03 & 0.93 & 0.73 \\
\hline 23 & Difficult wearing clothes & -0.09 & 0.11 & 0.91 & 0.81 \\
\hline 25 & Hard to exercise & 0.30 & -0.05 & 0.56 & 0.75 \\
\hline 14 & Uncomfortable moving & 0.41 & -0.03 & 0.49 & 0.80 \\
\hline 16 & Avoid swimsuits & 0.31 & 0.14 & 0.36 & 0.74 \\
\hline
\end{tabular}


Table 4 Reliability analysis of Social, Environment and Self subscales $(n=444)$

\begin{tabular}{|c|c|c|}
\hline $\begin{array}{l}\text { Scale and item content } \\
\text { (Item number) }\end{array}$ & $\begin{array}{l}\text { Corrected item- } \\
\text { total correlations }\end{array}$ & $\begin{array}{l}\text { Cronbach's alpha } \\
\text { if Item deleted }\end{array}$ \\
\hline Social & & 0.95 \\
\hline Feel unattractive (5) & 0.79 & 0.95 \\
\hline Avoid photographs (6) & 0.74 & 0.95 \\
\hline Embarrassed to exercise (7) & 0.77 & 0.95 \\
\hline Embarrassed to eat (8) & 0.76 & 0.95 \\
\hline Avoid being noticed (9) & 0.78 & 0.95 \\
\hline Worry what people say (10) & 0.80 & 0.95 \\
\hline $\begin{array}{l}\text { Uncomfortable at social } \\
\text { events (11) }\end{array}$ & 0.85 & 0.95 \\
\hline Feel like a loser (12) & 0.80 & 0.95 \\
\hline $\begin{array}{l}\text { Hard finding a boyfriend } \\
\text { or girlfriend (19) }\end{array}$ & 0.76 & 0.95 \\
\hline People stare (20) & 0.84 & 0.95 \\
\hline Not included (21) & 0.83 & 0.95 \\
\hline Self & & 0.90 \\
\hline Feel depressed (1) & 0.84 & 0.86 \\
\hline Feel ashamed (2) & 0.85 & 0.85 \\
\hline $\begin{array}{l}\text { Uncomfortable with } \\
\text { skinny people (3) }\end{array}$ & 0.70 & 0.91 \\
\hline Hide my body (4) & 0.75 & 0.89 \\
\hline Environment & & 0.90 \\
\hline Uncomfortable moving (14) & 0.78 & 0.88 \\
\hline Avoid swimsuits (16) & 0.69 & 0.90 \\
\hline Difficult wearing clothes (23) & 0.84 & 0.86 \\
\hline Difficult finding clothes (24) & 0.77 & 0.88 \\
\hline Hard to exercise (25) & 0.73 & 0.89 \\
\hline
\end{tabular}

Dropping any one item from the factor had no effect on coefficient alpha.

We further evaluated the one- and three-factor models using confirmatory factor analysis. In the one-factor model, all 21 items were hypothesized to load on one common factor; all the items were treated as continuous; and the error terms were left uncorrelated. In the three-factor model, the first factor was hypothesized to have 12 indicator items corresponding to the Social domain; the second factor was hypothesized to have 4 indicator items corresponding to Self domain; and the third factor was hypothesized to have five indicator items corresponding to Environment domain (see Fig. 1). Further, the three factors were hypothesized to be correlated (as in the oblique factor rotations), the factor loadings for the first item in each factor was set equal to 1.0 to identify the model, the items were treated as continuous, and the error terms were left uncorrelated. The CFI, TLI and RMSEA for the one-factor model were 0.84, 0.82 and 0.13 , respectively. By contrast, the CFI, TLI and RMSEA for the three-factor model were $0.90,0.89$ and 0.10 , respectively. Because the one-factor and three-factor models are nested, relative fit can be evaluated using the model log-likelihoods. The difference in model log-likelihoods between the one- and three-factor models was 264.13 with $3^{\circ}$ of freedom difference. This difference was highly significant $(P<0.001)$, indicating that the three-factor model fit the data significantly better than the one-factor model.

Test-retest reliability was evaluated for the Social, Self and Environment factors and the one-factor model with an intraclass correlation coefficient (ICC) from a two-way random effects ANOVA model. The ICC was 0.73 for the Social factor, 0.71 for the Self factor, 0.73 for Environment factor and 0.77 for the one-factor model. In general, ICCs of 0.70 or greater are acceptable for group comparisons in randomized clinical trials and other clinical research [32].

\section{Construct validity}

The zBMI was negatively correlated with Self $(-0.34$, $P<0.01)$, Social $(-0.38, P<0.01)$ and Environment $(-0.43, P<0.01)$ and with the one-factor model $(-0.41$, $P<0.01$ ), indicating that as weight increased, weightspecific QOL decreased. The CDI was also negatively correlated with Self $(-0.48, P<0.01)$, Social $(-0.59$, $P<0.01)$, Environment $(-0.49, P<0.01)$ and the onefactor model $(-0.58, P<0.01)$, indicating that as depression scores increased, weight-specific QOL scores decreased. Finally, the YQOL-R scores were positively correlated with the Self $(0.48, P<0.01)$, Social $(0.58$, $P<0.01)$, Environment $(0.51, P<0.01)$ and one-factor scores $(0.57, P<0.01)$, providing further evidence of construct validity.

\section{Discussion}

This results of this study show that the YQOL-W has good psychometric properties including reliability and construct validity in a community sample of African American, Mexican American and white children and adolescents of 11-18 years of age. Exploratory factor analysis of 25 candidate items yielded three factors reflecting Social-, Environmental- and Self-related aspects of weight-specific QOL. Due to high inter-correlations among these three factors, a one-factor model was also considered. Confirmatory factor analysis showed that the three-factor and one-factor models fit the data well. The one-factor model had the advantage of parsimony, whereas the three-factor model fit the data somewhat better and parallels previous multidimensional conceptualizations of QOL in children and adolescents $[6,11]$. Our results suggest that researchers can choose between the one- and three-factor YQOL-W models based on the particular needs of their study. 
Fig. 1 Confirmatory factor analysis for the YQOL-W three model with model fit statistics and standardized results

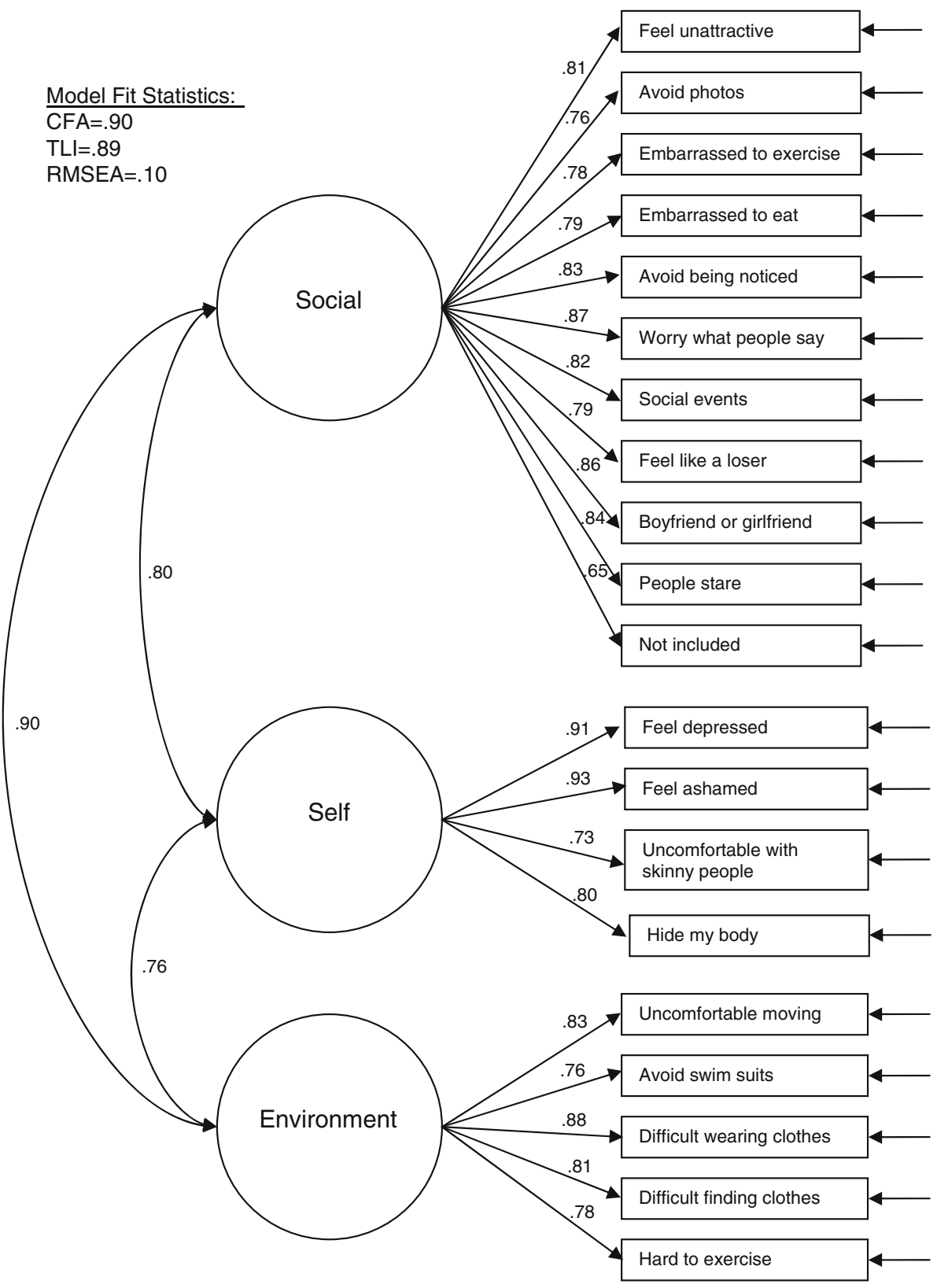

In this study, there was a significant inverse association between BMI and the one-factor YQOL-W score and the three-factor YQOL-W scores (Self, Social and Environment). Specifically, we found an inverse relationship between BMI and the YQOL-W scores. This is consistent with other studies of QOL and weight among children and adolescents. In a recent meta-analysis of quality of life in overweight children and adolescents [11], the inverse correlation between BMI and overall QOL was -0.70 $(P<0.01)$ with the greatest impairments in physical and social functioning. In this study, the magnitude of the correlation between BMI and the one-factor YQOL-W was somewhat smaller $(r=-0.41)$, and the magnitude of the correlations between BMI and the various dimensions of the YQOL-W were smaller (Self, $r=-0.34$; Social, $r=-0.38$; Environment, $r=-0.43$ ). Differences between the YQOL-W and the instruments used in other studies and/or differences in the populations studied may account for these discrepancies.

The YQOL-W has several advantages over previously developed weight-targeted measures of QOL. Specifically, the YQOL-W item pool was developed with ethnographic methods drawing directly on the experiences of and the language used by children and adolescents describing the effects of weight on QOL. This approach ensures to the greatest degree possible that the item content is valid. By contrast, many existing measures consist of items that were developed wholly upon the opinions of the investigators 
themselves in addition to the opinions of other experts without the involvement of any children or adolescents. This includes the Impact of Weight on Quality of Life (IWQOL) [33] and the Sizing Me Up [34]. Another methodological strength of the YQOL-W is that the initial qualitative research and subsequent survey administration included significant numbers of children and adolescents of multicultural backgrounds including African Americans and Mexican Americans. The inclusion of a multicultural group of study participants helps to ensure that the YQOL$\mathrm{W}$ items will be applicable in diverse groups of children and adolescents. This is particularly important in light of the epidemiology of childhood obesity. Minority children and adolescents are at greater risk and have a higher prevalence of overweight and obesity than their nonminority counterparts [2].

This study has the limitation that the samples of African American, Mexican American and white youth were not representative of all African American, Mexican American and white youth, and therefore their responses may not completely reflect the views of all members of these respective groups. This is a limitation inherent to all studies that use convenience sampling methods. More studies are needed to confirm our results in other patient populations and to further characterize the measurement properties in the YQOL-W. Finally, the analyses in this study are based on classical test theory only. Future research should include the use of modern test theory including item response theory, to characterize the YQOL-W scales. Future papers will address the ability of the YQOL-W to detect changes in weight.

Open Access This article is distributed under the terms of the Creative Commons Attribution Noncommercial License which permits any noncommercial use, distribution, and reproduction in any medium, provided the original author(s) and source are credited.

\section{References}

1. Bethell, C., Simpson, L., Stumbo, S., Carle, A. C., \& Gombojav, N. (2010). National, state, and local disparities in childhood obesity. Health Aff (Millwood), 29(3), 347-356.

2. Ogden, C. L., Carroll, M. D., Curtin, L. R., McDowell, M. A., Tabak, C. J., \& Flegal, K. M. (2006). Prevalence of overweight and obesity in the United States, 1999-2004. JAMA, 295(13), 1549-1555.

3. Cruz, M. L., Shaibi, G. Q., Weigensberg, M. J., Spruijt-Metz, D., Ball, G. D., \& Goran, M. I. (2005). Pediatric obesity and insulin resistance: Chronic disease risk and implications for treatment and prevention beyond body weight modification. Annual Review of Nutrition, 25, 435-468.

4. Wright, C. M., Parker, L., Lamont, D., \& Craft, A. W. (2001). Implications of childhood obesity for adult health: Findings from thousand families cohort study. BMJ, 323(7324), 1280-1284.

5. Power, C., Lake, J. K., \& Cole, T. J. (1997). Measurement and long-term health risks of child and adolescent fatness.
International Journal of Obesity and Related Metabolic Disorders, 21(7), 507-526.

6. Edwards, T. C., Huebner, C. E., Connell, F. A., \& Patrick, D. L. (2002). Adolescent quality of life, part I: Conceptual and measurement model. Journal of Adolescence, 25(3), 275-286.

7. Group WHOQoL. (1994). The development of the world health organization quality of life assessment instrument (WHOQOL). In J. Orley \& W. Kuyken (Eds.), Quality of life assessment: International perspectives (pp. 41-57). Berlin: Springer.

8. Doyal, L., \& Gough, I. (1991). The theory of human need. New York: Guilford Press.

9. Puhl, R., \& Brownell, K. D. (2001). Bias, discrimination, and obesity. Obesity Research, 9(12), 788-805.

10. Wardle, J., \& Cooke, L. (2005). The impact of obesity on psychological well-being. Best Practice and Research. Clinical Endocrinology and Metabolism, 19(3), 421-440.

11. Tsiros, M. D., Olds, T., Buckley, J. D., Grimshaw, P., Brennan, L., Walkley, J., et al. (2009). Health-related quality of life in obese children and adolescents. International Journal of Obesity (London), 33(4), 387-400.

12. Varni, J. W., Seid, M., \& Rode, C. A. (1999). The PedsQL: Measurement model for the pediatric quality of life inventory. Medical Care, 37(2), 126-139.

13. Starfield, B., Bergner, M., Ensminger, M., Riley, A., Ryan, S., Green, B., et al. (1993). Adolescent health status measurement: Development of the child health and illness profile. Pediatrics, 91(2), 430-435.

14. Kolotkin, R. L., Crosby, R. D., Kosloski, K. D., \& Williams, G. R. (2001). Development of a brief measure to assess quality of life in obesity. Obesity Research, 9(2), 102-111.

15. WHOQOL. (1997). Measuring quality of life: World Health Organization, Abuse DoMHaPoS.

16. Skalicky, A. M., Edwards, T. C., Flores, Y. N., Hobby, A. D., Morales, L. S., Patrick, D. L. (2010). Perceptions of multicultural youth about weight and body size. International Society for Quality of Life Research. http://www.isoqol.org/2009conference/ pdf/2009ConferenceProgram.pdf. Accessed 30 June.

17. Kovacs, M. (1992). The children's depression inventory (CDI). Toronto, Ontario: Multi-Health Systems, Inc.

18. Patrick, D. L., Edwards, T. C., \& Topolski, T. D. (2002). Adolescent quality of life, part II: initial validation of a new instrument. Journal of Adolescence, 25(3), 287-300.

19. Kuczmarski, R. J., Ogden, C. L., Grummer-Strawn, L. M., Flegal, K. M., Guo, S. S., Wei, R. et al. (2000). CDC growth charts: United States. Advance Data, 314, 1-27.

20. Bartlett, M. S. (1950). Tests of significance in factor analysis. British Journal of Psychology, 3, 77-85.

21. Guttman, L. (1954). Some necessary conditions for commonfactor analysis. Psychometrika, 19, 149-161.

22. Kaiser, H. F. (1960). The application of electronic computers to factor analysis. Educational and Psychological Measurement, 20, 141-151.

23. Pett, M. A., Lackey, N. R., \& Sullivan, J. J. (2003). Making sense of factor analysis: The use of factor analysis for instrument development in health care research. Thousand Oaks, CA: Sage Publications.

24. Catell, R. B. (1966). The scree test for the number of factors. Multivariate Behavioral Research, 1, 245-276.

25. Hays, R. D. (1987). PARALLEL: A program for performing parallel analysis. Applied Psychologial Measurement, 11, 58.

26. Hayton, J. C., Allen, D. G., \& Scarpello, V. (2004). Factor retention decisions in exploratory factor analysis: A tutorial on parallel analysis. Organizational Research Methods, 7, 191-205.

27. Brown, T. A. (2006). Confirmatory factor analysis for applied research. New York: The Guilford Press. 
28. SPSS statistics base 17.0 user's guide. (2008). Chicago: SPSS Inc.

29. Muthen, L. K., Muthen, B. O. (1998-2007). MPLUS user's guide. Fifth edition. Los Angeles, CA: Muthen \& Munten.

30. Yeomans, K. A., \& Golder, P. A. (1982). The Kaiser-Guttman criterion as a predictor of the number of common factors. Journal of the Royal Statistical Society, 31, 221-229.

31. Netemeyer, R. G., Bearden, W. O., \& Sharma, S. (2003). Scaling procedures: Issues and applications. Thousand Oaks, CA: Sage Publications.

32. Lohr, K. N. (2002). Assessing health status and quality-of-life instruments: Attributes and review criteria. Quality of Life Research, 11(3), 195-205.
33. Kolotkin, R. L., \& Crosby, R. D. (2002). Psychometric evaluation of the impact of weight on quality of life-lite questionnaire (IWQOL-lite) in a community sample. Quality of Life Research, 11(2), 157-171.

34. Zeller, M. H., \& Modi, A. C. (2009). Development and initial validation of an obesity-specific quality-of-life measure for children: Sizing me up. Obesity (Silver Spring), 17(6), 1171-1177. 